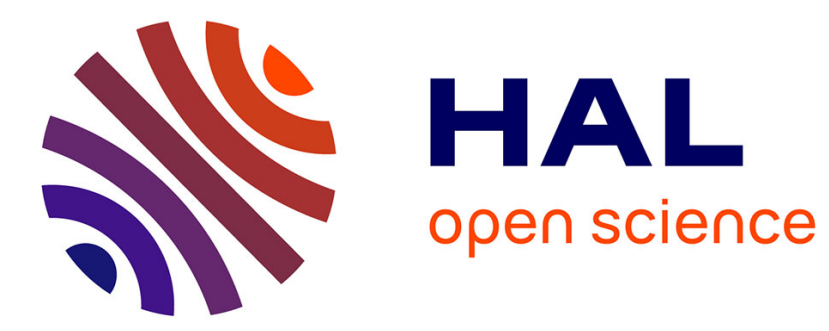

\title{
Memory effect of the molecular topology of lamellar polyethylene on the strain-induced fibrillar structure
}

\author{
S. Humbert, O. Lame, J.-M. Chenal, Roland Seguela, G. Vigier
}

\section{To cite this version:}

S. Humbert, O. Lame, J.-M. Chenal, Roland Seguela, G. Vigier. Memory effect of the molecular topology of lamellar polyethylene on the strain-induced fibrillar structure. European Polymer Journal, 2012, 48 (6), pp.1093-1100. 10.1016/j.eurpolymj.2012.03.010 . hal-01834902

\section{HAL Id: hal-01834902 \\ https://hal.science/hal-01834902}

Submitted on 13 Apr 2021

HAL is a multi-disciplinary open access archive for the deposit and dissemination of scientific research documents, whether they are published or not. The documents may come from teaching and research institutions in France or abroad, or from public or private research centers.
L'archive ouverte pluridisciplinaire HAL, est destinée au dépôt et à la diffusion de documents scientifiques de niveau recherche, publiés ou non, émanant des établissements d'enseignement et de recherche français ou étrangers, des laboratoires publics ou privés. 


\title{
Memory effect of the molecular topology of lamellar polyethylene on the strain-induced fibrillar structure
}

\author{
S. Humbert, O. Lame* , J.-M. Chenal, R. Seguela*, G. Vigier \\ Université de Lyon, Laboratoire MATEIS, INSA de Lyon-CNRS-UMR5510, Bâtiment Blaise Pascal, Campus de la Doua, 69621 Villeurbanne, France
}

The fibrillar structure that develops upon drawing of semi-crystalline polymers has been investigated at room temperature by means of in situ SAXS for a series of ethylene copoly-mers crystallized through various thermal treatments. The long period of the microfibrils for any given material proved to be only dependent on the experimental conditions of the drawing. This suggested the occurrence of a destruction and reconstruction of the semi-crystalline structure via fragmentation accompanied with melting-recrystallization. However, the diameter of the microfibrils proved to keep the memory of the lamellar microstructure via a correlation with the content of interphase at the crystal-amorphous boundary. A physical explanation is proposed for these apparently antagonist findings. The memory of the lamellar semi-crystalline microstructure is completely erased in the microfibrils owing to the melting-recrystallization process. In contrast, the diameter of the fibrils keeps the memory of the chain topology to which a major role is ascribed in the strain-induced fragmentation of the crystalline lamellae.

\section{Introduction}

The deformation at large strains of semi-crystalline polymers often proceed via a plastic instability or necking due to the successive occurrence of strain-softening and strain-hardening [1-4]. At a microscopic level, this phenomenon involves a tremendous metamorphosis of the semi-crystalline lamellar microstructure known as fibrillar transformation. Based on plentiful studies regarding polyethylene (PE), this transformation has been described as a process of fragmentation of the lamellar crystals into blocks that rearrange into fibrils like strings of pearls via chain unfolding from the fracture surface of the crystal blocks [5-13].

The most commonly studied feature of the fibrillar structure is the long period, $L_{p f}$, characteristic of the regular stacking of crystalline and amorphous phases. Generally,

\footnotetext{
* Corresponding authors. Tel.: +33 04724361 29; fax: +33 04724385 28 (R. Seguela).

E-mail addresses: olivier.lame@insa-lyon.fr (O. Lame), roland.segue la@insa-lyon.fr (R. Seguela).
}

$L_{p f}$ is quite different from the crystalline lamella stacking of the isotropic material, $L_{p}$, and essentially depends on the draw conditions, i.e. the draw rate and the draw temperature, $T_{d}$. Moreover, the $L_{p f}=f\left(T_{d}\right)$ relationship proved to be very similar to the dependency of isotropic materials on the temperature of isothermal crystallization or annealing $[14,15]$. This finding led number of authors to conclude that the fibrillar transformation is accompanied with a strain-induced melting-recrystallization process. This process may result either from the powerful self-heating effect in relation to the high level of instantaneous plastic work [16] or from destruction by chain-unfolding of the crystals $[17,18]$ that recrystallize immediately due to the high chain mobility and high thermodynamic driving force of PE above room temperature [19]. In a meticulous study by transmission electron microscopy of the stretching of thin PE films, Adams et al. [12] disclosed the concomitant occurrence of several deformation mechanisms such as lamellar crystal shear, crystal block slip, lamellar fragmentation and oriented recrystallization of chains unfolded from the crystal fragments. 
Several descriptive models at a molecular scale have been proposed for this process. These models assume different scenarios for the mechanism of lamella fragmentation [6-13] that has never been actually captured due to its highly unstable character. Moreover, the chain unfolding mechanism also remains mysterious due to impossible access to direct observation. The mosaic block structure of the crystalline lamellae of PE has been suggested to play a role in the initiation of lamellae fragmentation owing to the presence of crystallographic defects that are likely to promote localized crystal slip [20-25]. The chain topology at the surface of the lamellar crystals is also prone to generate stress concentration contributing to the initiation of the crystallite fragmentation [26-31]. Moreover, the molecular architecture of the polymer, including concentration and distribution of co-units and molar weight distribution as well, and its morphogenesis, namely the way the semi-crystalline structure was formed during the crystallization stage, are two major factors in the generation of crystallographic defects and the setting of the chain topology in PE. Therefore, both these factors are expected to influence the completion of the fibrillar transformation beyond necking.

A number of authors have reported on the influence of the chain topology of the initial lamellar structure including entanglements and intercrystalline tie molecules on the natural draw ratio and the post-yield strain-hardening of PE-based materials [8,32-41]. The fact that these two macroscopic features of the fibrillar structure of the drawn material depend on the initial structure of the isotropic material seems somewhat contradictory with the $L_{p f}$ dependence on the draw conditions only. One may therefore wonder which characteristic of the fibrillar structure keeps the memory of the morphogenesis of the isotropic lamellar polymer?

In a series of papers we reported on the role of thermal treatment on the molecular topology of ethylene copolymers and the incidence of mechanical properties. The low strain tensile behavior and yielding $[30,41,42]$ as well as the trend for strain-induced cavitation [31] were shown to strongly depend on the density of stress transmitters such as tie chains and chain entanglements. Investigating the effect of the chain topology on the fibrillar transformation that occurs beyond necking appeared as an opportunity to check the robustness of our approach of the structure-property relationships in semi-crystalline polymers. In this paper we more specifically address the mechanism of lamella fragmentation and the occurrence of melting-recrystallization.

\section{Experimental}

The materials supplied by Total-Petrochemicals (Feluy, Belgium) consisted of four ethylene-hexene copolymers synthesized by means of Philips chromium-oxide catalysis and having various amounts of hexene co-units. The molecular and physical characteristics of the four row materials are given in Table 1 . The copolymer pellets were compression-molded at $170{ }^{\circ} \mathrm{C}$ into $500 \mu \mathrm{m}$ thick sheets and quenched into water at room temperature (RT). This
Table 1

Molecular and physical characteristics of the row materials.

\begin{tabular}{lllll}
\hline Materials & {$\left[C_{6}\right]^{\mathrm{a}}(\mathrm{mol} \%)$} & $M_{n}(\mathrm{kDa})$ & $M_{w}(\mathrm{kDa})$ & $T_{c}\left({ }^{\circ} \mathrm{C}\right)$ \\
\hline PE-A & 1.8 & 14.3 & 231 & 114 \\
PE-B & 0.8 & 15.8 & 187 & 114 \\
PE-C & 0.1 & 15.4 & 216 & 124 \\
PE-D & 0.1 & 15.0 & 229 & 124 \\
\hline
\end{tabular}

a $\left[C_{6}\right]$ accuracy is $\pm 0.1 \%$.

molding methods prevents orientation effects that are likely to bias mechanical data. A part of these sheets was annealed at a temperature close to the onset of the crystallization exotherm, as indicated through the $T_{c}$ data in Table 1 , for $15 \mathrm{~h}$ in a temperature-regulated silicone-oil bath. The sheets were subsequently cooled down to RT at a cooling rate of $10^{\circ} / \mathrm{min}$. Another part of the sheets was melted again at $170{ }^{\circ} \mathrm{C}$ and submitted to isothermal crystallization from the melt at the same temperature as the annealing treatment, for $15 \mathrm{~h}$ using the same silicone-oil bath. In order to prevent oil pollution of the samples during both treatments, the samples were squeezed between aluminum plates tightly jointed thanks to a silicone rubber gasket.

Differential scanning calorimetry (DSC) was carried out on a Perkin Elmer apparatus at a heating or cooling rates of $10^{\circ} \mathrm{C} / \mathrm{min}$, using samples of $5-7 \mathrm{mg}$. The temperature and heat flow scales were calibrated with high purity indium and zinc samples at the same heating rate. The crystallization temperature, $T_{c}$, and the melting temperature, $T_{m}$, were measured at the peak of the crystallization exotherm and the melting endotherm, respectively. The crystal weight fraction was computed from the ratio, $X_{c}=\Delta H_{m} / \Delta H_{m}{ }^{\circ}$, where $\Delta H_{m}$ is the melting enthalpy of the sample and $\Delta H_{m}{ }^{\circ}=290 \mathrm{~J} / \mathrm{g}$ that of the perfect orthorhombic polyethylene crystal [43]. The standard deviation of the $X_{c}$ data is about $1 \%$. Crystallinity measurements regarding drawn samples assumed no recrystallization during the heating scan, as previously discussed in a recent paper dealing with the same polymers [42].

Density measurements were carried out in a watermethanol gradient column regulated at $23^{\circ} \mathrm{C}$. Calibration was performed by means of glass beads of precisely known density in the range of interest. The sample density, $\rho$, was determined with an accuracy of $5.10^{-4} \mathrm{~g} / \mathrm{cm}^{3}$.

Raman spectroscopy was carried out on a LabRAM Aramis UV-Vis apparatus equipped with a 600 lines/mm grating, using the $633 \mathrm{~nm}$ radiation of a He-Ne source. This technique was used to assess the weight fraction of crystal-amorphous interphase, $X_{i}$, according to Strobl \& Hagedorn method [44]. More details on the experimental procedure and spectrum analysis are provided elsewhere [42]. The accuracy of the $X_{i}$ data was $\pm 1 \%$ in absolute value.

Tensile drawing experiments were conducted at room temperature (RT) on an Instron tensile testing machine. The dumbbell-shaped tensile specimens having $22 \mathrm{~mm}$ in gauge length, $5 \mathrm{~mm}$ in width were cut out from the sheets. All materials were drawn till propagation of the necking over the whole sample length. The natural draw ratio, $\lambda_{N}$ was measured on the drawn samples immediately after 
unloading. The high reproducibility of the data (standard deviation $\approx 2 \%$ ) gives indication of homogeneity of the sheets and lack of structural defects.

Small-angle X-ray scattering (SAXS) experiments were performed on the BM2-D2AM beamline of the European Synchrotron Radiation Facility (ESRF, Grenoble France) using a wavelength $\lambda=0.154 \mathrm{~nm}$. The 2D-SAXS patterns recorded on a CCD camera (Ropper Scientific) were corrected for geometry and intensity distortions. The Lorentz-corrected intensity profiles of the isotropic samples, $I q^{2}(q)$ where $q=4 \pi \sin \theta / \lambda$ is the scattering vector, were obtained by azimuthal integration of the $2 \mathrm{D}$ patterns. The long period of the lamellar stacking, $L_{p}$, was determined from the relation,

$L_{p}=2 \pi / q^{\max }$

where $q^{\max }$ is the scattering vector at the apex of the SAXS correlation peak. The standard deviation of the $L_{p}$ data does not exceed $1 \mathrm{~nm}$. In situ SAXS measurements were also carried out upon drawing at the stage of thoroughly propagated neck at RT using a home-made drawing stage described elsewhere [31]. The intensity profiles along the meridian were obtained by projection of the 2D-patterns on the meridian according to Stribeck's method [45], before applying the Lorentz-correction factor.

The crystal thickness, $L_{c}$, was computed from the following relation:

$L_{c}=L_{p} X_{c} \rho / \rho_{c}$.

where $\rho_{c}=1.00 \mathrm{~g} / \mathrm{cm}^{3}$ is the density of the crystalline phase [43]. This relation assumes much larger length and width of the crystalline lamellae as compared with thickness.

All the physical data regarding the thermally treated samples are reported in Table 2.

\section{Results}

Fig. 1a shows an example of the in situ SAXS pattern recorded during drawing the quenched PE-A sample at the stage of thoroughly propagated neck. Structural data regarding the microfibril long period were obtained from the analysis of the Lorentz-corrected radial intensity profile along the meridian whereas the transverse dimension of the microfibrils was assessed from the Lorentz-corrected intensity profile transverse to the meridian reflection. Fig. 1b shows a molecular sketch of the fibrillar structure together with its characteristic dimensions. Fig. 1a also shows the appearance of a diffuse equatorial scattering (a)

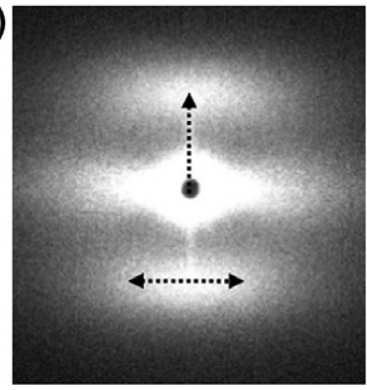

(b)

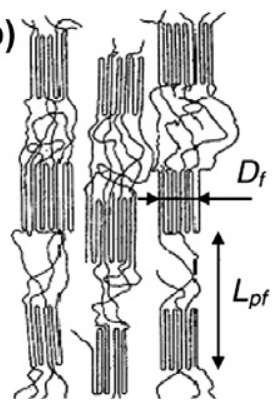

Fig. 1. Structural analysis of the fibrillar structure: (a) in situ SAXS pattern recorded from the center of the neck of quenched PE-A; (b) molecular model (draw axis vertical).

originating from interfibrillar cavitation in the central part of the pattern. Except for PE-A, this central scattering was so intense in the case of annealed and isothermal specimens that it merged onto the meridian scattering, prohibiting quantitative analysis of the SAXS pattern.

In Fig. 2 is shown the Lorentz-corrected intensity profile of the quenched isotropic PE-A sample computed from azimuthal integration of the 2D scattering pattern. The intensity profile of the necked sample also reported in Fig. 2 is obtained by projection of the 2D pattern on the meridian axis (see Fig. 1a). The strong difference in intensity results from several factors: the thinning down of the drawn sample, the loss of stacking regularity due to the much smaller extent of the lamellar crystals and the shift to higher $q$ value of the correlation peak. Nevertheless, it is worth noticing that the shape and width of the scattering peak are rather similar. The same remark applies to the other polymers.

The long period, $L_{p f}$, of the fibrillar samples is reported in Fig. 3 as a function of the initial long period, $L_{p}$, of the isotropic materials (see Table 2). As already pointed out in the comment of Fig.1, the intense central scattering arising from an early interfibrillar cavitation prohibited quantitative analysis of the meridian scattering of annealed and isotherm samples except PE-A. Thereby, data regarding PE$\mathrm{B}, \mathrm{PE}-\mathrm{C}$ and PE-D are only for the quenched samples.

Both $L_{p}$ and $L_{p f}$ increase along with the crystallinity of the isotropic materials. However, in account of data accuracy, $L_{p f}$ is systematically lower than $L_{p}$ of the corresponding isotropic quenched material. Moreover, $L_{p f}$ is similar for the three PE-A samples, irrespective of the morphogenesis of the lamellar microstructure induced by the thermal treatment in the isotropic state. This corroborates the pre-

Table 2

Structural and physical characteristics of the copolymers with various thermal treatments $(\mathrm{Q}=$ quenched; $\mathrm{A}=$ annealed; $\mathrm{I}=\mathrm{isotherm})$ : crystallinity from DSC, $X_{c}$; density, $\rho$; interphase content from Raman spectroscopy, $X_{i}$; natural draw ratio, $\lambda_{N}$; average fibril diameter of the necked sample from SAXS, $D_{f}$

\begin{tabular}{|c|c|c|c|c|c|c|c|}
\hline Material & $X_{c}(\%)$ & $\rho\left(\mathrm{g} / \mathrm{cm}^{3}\right)$ & $X_{i}(\%)$ & $L_{p}(\mathrm{~nm})$ & $T_{m}\left({ }^{\circ} \mathrm{C}\right)$ & $\lambda_{N}$ & $D_{f}(\mathrm{~nm})$ \\
\hline PE-A Q & 49 & 0.931 & 13 & 17 & 124.5 & 3.5 & 2.8 \\
\hline PE-A A & 52 & 0.937 & 14 & 23 & 126.0 & 4.0 & 2.0 \\
\hline PE-A I & 53 & 0.940 & 1 & 24 & 128.0 & 4.7 & 1.8 \\
\hline PE-B Q & 54 & 0.940 & 8 & 19 & 128.0 & 4.2 & 3.1 \\
\hline PE-C Q & 65 & 0.948 & 5 & 20 & 129.5 & 4.5 & 4.0 \\
\hline PE-D Q & 69 & 0.951 & 4 & 23 & 131.5 & 5.0 & 5.1 \\
\hline
\end{tabular}




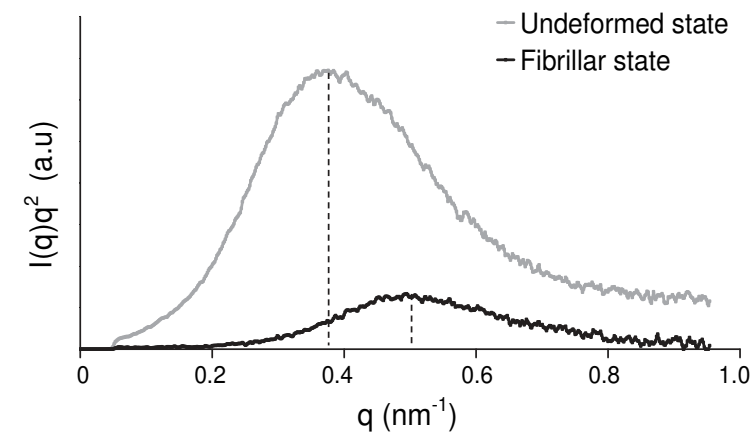

Fig. 2. Lorentz-corrected SAXS intensity profiles of quenched PE-A: $(\longrightarrow$ ) isotropic and (-) neck-drawn samples.

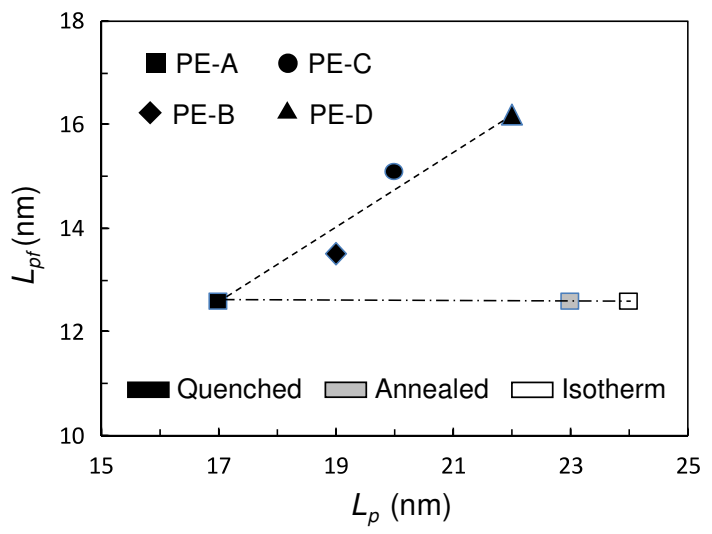

Fig. 3. $L_{p f}$ fibrillar versus $L_{p}$ isotropic.

viously reported $L_{p f}$ dependence on the draw conditions only and vouch in favor of a complete reconstruction of the periodic structure during the fibrillar transformation, namely the destruction-reconstruction or melting-recrystallization scheme.

In Table 3 are reported the crystallinity data of the necked materials. This Table includes the data regarding the annealed and isotherm samples of polymers PE-B, PE$C$ and PE-D that could not be investigated by SAXS. Comparison of the data of every necked sample with its isotropic counterpart prior to drawing indicates that the crystallinity of the fibrillar materials, $X_{c f}$, is little if any dependent of the initial isotropic morphology. It mainly depends on the polymer nature and the draw conditions: more particularly, $X_{c f}$ is roughly intermediate between the $X_{c}$ value of the quenched and annealed samples of the corresponding isotropic material. As a matter of fact, the actual recrystallization temperature should be some- what above the draw temperature RT (also the quenching temperature) owing to the well-known self-heating effect in the neck shoulder where a great amount of plastic work is locally transformed into heat [16]. The actual temperature should be yet not as high as that of annealing.

The $X_{c f}$ invariance with regard to the initial morphology is particularly obvious for PE-B and PE-C which display substantial variations in $X_{c}$ as a function of crystallization conditions. PE-A is not much demonstrative on this point due to the fact that $X_{c}$ is already very little sensitivity to thermal treatment. Regarding PE-D, $X_{c f}$ seems to be somewhat sensitive to the initial morphogenesis. One may suspect in this case that the very large change in crystallinity of the samples in the order quenched $<$ annealed $<$ isotherm entails an increasingly unstable plastic deformation that should result in more localized self-heating. This hypothesis is thoroughly supported by the large increase of natural draw ratio of PE-D from 5 to 7 in the same order indicating increasing plastic instability. As a result, the local temperature in the sample during necking may jump to higher values in the order quenched $<$ annealed $<$ isotherm, involving thus an improved crystallization potentiality. This is an indirect effect of the initial morphology that could be annihilated under isothermal drawing, i.e. at very low strain rate.

The above findings regarding both $L_{p f}$ and $X_{c f}$ suggest that there is no direct memory effect of the initial morphology on the fibrillar structure. This is surprising in consideration that the natural draw ratio-which is a macroscopic manifestation of the fibrillar transformationis fairly well correlated with the initial morphology, as shown in a previous study regarding the same materials as the present four ones, for the three different thermal treatments (see Fig.4 in Ref. [41]). This apparent inconsistency between macroscopic and microscopic findings is analogous to the one previously pointed out in the introduction and suggests that a memory effect of the initial morphology on the fibrillar structure does exist. One may therefore reasonably expect the existence of a fingerprint of the initial microstructure on one of the structural features of the microfibrils.

Studies dealing with the characterization of other structural items than $L_{p f}$ in the microfibrillar components of draw polymers are not abundant. Detailed analyses of the SAXS patterns of fibers have yet been an early issue in the domain of structure-property relationships of polymers in view of improving their use properties [46-50]. It is rather conventional to associate the scattering objects to the individual microfibrils embedded in a medium of lower electron density consisting of amorphous chains and cavities. Alternatively, the scattering elements can be identified as the crystal blocks within the microfibrils. The

Table 3

Crystallinity data of the thermally treated isotropic samples, $X_{c}$, and the corresponding neck-drawn samples, $X_{c f}(\mathrm{Q}=$ quenched; $\mathrm{A}=$ annealed; $\mathrm{I}=\mathrm{isotherm})$.

\begin{tabular}{|c|c|c|c|c|c|c|c|c|c|c|c|c|}
\hline \multirow{2}{*}{$\begin{array}{l}\text { Materials } \\
\text { Thermal treatment }\end{array}$} & \multicolumn{3}{|c|}{ PE-A } & \multicolumn{3}{|c|}{ PE-B } & \multicolumn{3}{|c|}{ PE-C } & \multicolumn{3}{|c|}{ PE-D } \\
\hline & $\mathrm{Q}$ & A & I & Q & A & I & Q & A & I & Q & A & I \\
\hline$X_{c}(\%)$ & 51 & 52.5 & 53 & 54 & 62 & 65 & 65 & 73 & 75 & 70 & 77 & 79.5 \\
\hline$X_{c f}(\%)$ & 51 & 53.5 & 53.5 & 59 & 59 & 60 & 67 & 64 & 69 & 72 & 75 & 78.5 \\
\hline
\end{tabular}




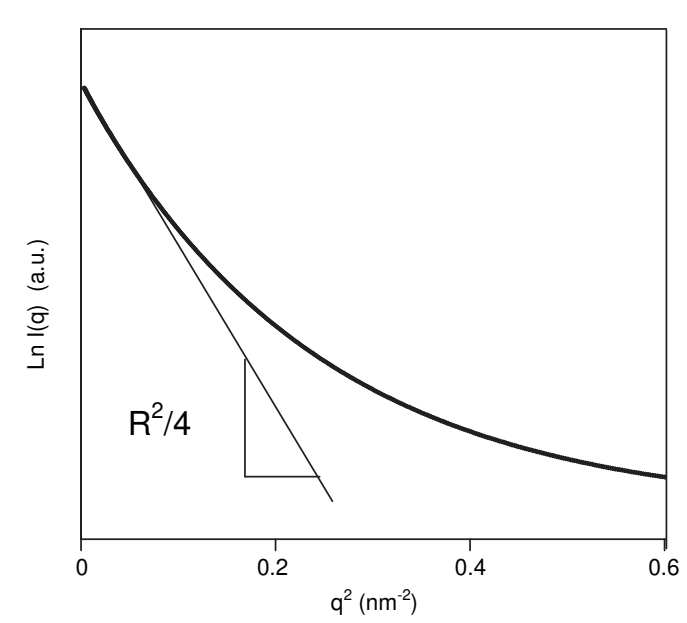

Fig. 4. Guinier's plot of the meridian scattering of neck-drawn PE-Aquenched.

corresponding models consist of either elongated cylinders or discs, respectively. In both instances, the analysis of the radial contribution of the scattering factor can be readily performed via the so-called Guinier's approximation leading to an estimation of the radial size of the scattering element which proved to be little dependent on the model.

In the case of a scattering cylinder, the Guinier's approximation function is [51],

$I(q)=I_{0} \exp \left(-q^{2} R_{f}^{2} / 4\right)$

where $R_{f}$ is the diameter of the scattering cylinder. Eq. (3) is only valid for $q R_{f} \ll 1$. This relation is assumed to be valid in the case of a population of scattering cylinders having a narrow distribution of diameters and without interferences. In this case $R_{f}$ is the weight-average value of the diameter distribution.

In practice, the Guinier's analysis should be performed about the center of the SAXS pattern where $q R_{f} \ll 1$ in all directions. Unfortunately, the presence of cavities generating an intense equatorial scattering (Fig. 1a) prohibits the analysis of the microfibril contribution in this region. However, benefiting from the unidirectional character of the scattering factor of the highly oriented microfibrils along the meridian direction, it has been shown that the Guinier's analysis can be shifted up to the meridian scattering arising from the periodic stacking of the crystal blocks (Fig. 1a) [46-50].

An example of Guinier's plot is shown in Fig. 4 in the case of the neck-drawn sample of PE-A-quenched. It clearly appears that Guinier's approximation only fits at very low values of the scattering vector. The computed data of the microfibril diameter, $D_{f}=2 R_{f}$, for all samples are reported in Table 2. The $D_{f}$ standard deviation does not exceed $0.5 \mathrm{~nm}$.

Assuming that the fibrillar transformation results from the fragmentation of the crystalline lamellae, as it is largely admitted in literature, one may suspect that the concentration of stress transmitters, [ST], has a major role in the process. In Fig. 5a are plotted the $D_{f}$ data as a function of the natural draw ratio (see Table 2 ) which is a macroscopic representative of [ST]. The monotonic correlation for the four quenched polymers confirms the incidence on $D_{f}$ of the chain topology, in relation to the molecular architecture of the polymers. However, regarding the incidence of thermal treatment, the data of the PE-A samples crystallized under annealing or isothermal treatment strongly deviate from the previous relationship of the four quenched polymers (deviation largely exceeds data accuracy). This means that the chain topology resulting from the morphogenesis of the lamellar structure has a complex incidence on $D_{f}$.

From a microscopic standpoint Fig. 5b, shows the $D_{f}$ plot as a function of Nitta's topological factor, $L_{c} /[S T]^{0.5}$, where [ST] borrows from Brown's model [28]. Worth noticing is that Nitta's factor is featuring the average distance between neighbor stress transmitters (see Eq. (7) in Ref. [28]). Similar inconsistency appears between the behavior of the quenched samples and that of the annealed or isotherm samples that confirms the complex incidence on $D_{f}$ of the chain topology. More precisely, one may conclude that the concentration of stress transmitters is not the unique topological factor to be taken into account for the incidence of the chain topology on the microfibril diameter.

In their approach of the influence of thermal treatments on the fibrillar transformation of semi-crystalline polymers, Tarin and Thomas [9] suggested that all chain topology defects were likely to contribute in the initiation of crystal fragmentation. A number of previous studies regarding the structural habits of PE-based materials have reported on the existence of an interphase or transition region at the crystal-amorphous boundary [52-57]. The interphase weight fraction, $X_{i}$, was shown to depend on both the chain architecture and the crystallization conditions: high regularity chains as well as slow crystallization result in lower $X_{i}$ values. For this reason, the interphase was generally assigned to the gathering all kinds of topological defects arising from the chain-folding crystallization, namely chain entanglements, anchoring of tie molecules on the crystal, segregated co-units, irregular chain-folds, chain ends, etc.

The $D_{f}$ data have been plotted in Fig. 6 as a function of $X_{i}$ as determined from Raman spectroscopy (see Table 2). Though the correlation is not perfect, the data deviation from the average curve is much less than in Fig. 5a and b, and does not exceed the experimental accuracy. It is worth noticing that using the $X_{i}$ data computed from the difference of crystallinity between density and DSC measurements [42] would give a very similar correlation. Indeed, the two kinds of $X_{i}$ data display similar dependence on molecular architecture and thermal treatment, although being somewhat different. The correlation of Fig. 6 suggests thus that all chain topology defects located in the interphase contribute to the initiation of the crystal fragmentation events, not just the stress transmitters between crystallites such as tie chains and chain entanglements.

\section{Mechanism of fibril initiation}

Stress transmitters can intuitively be assigned a major role in the mechanism of microcrack initiation upon strain- 

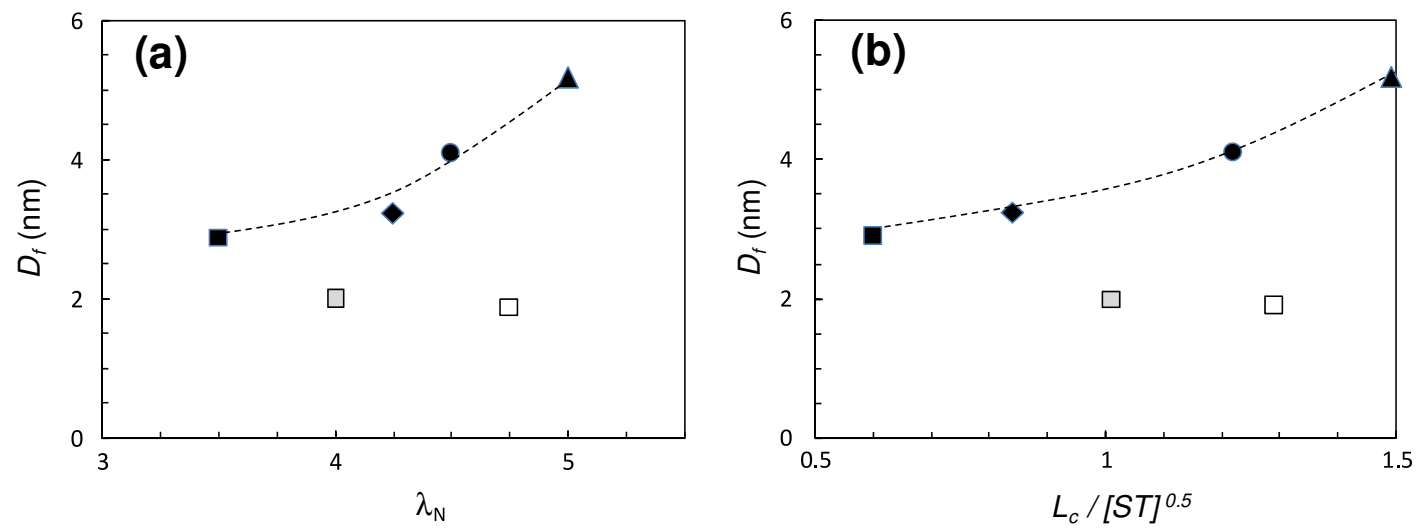

Fig. 5. $D_{f}$ versus (a) natural draw ratio and (b) Nitta's topological factor (same symbols as in Fig.3).

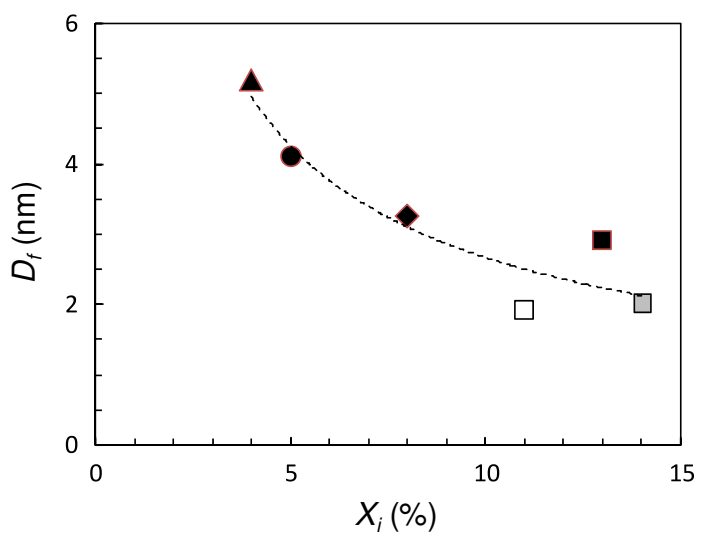

Fig. 6. Average microfibril diameter, $D_{f}$, as a function of interphase weight fraction, $X_{i}$ (same symbols as in Fig.3).

ing due to the generation of local stress concentration on the crystalline lamella surface. Then microcrack propagation will result into lamella fragmentation prior to fibrillar transformation. Therefore, the higher the concentration of stress transmitters the smaller the crystal block size, and

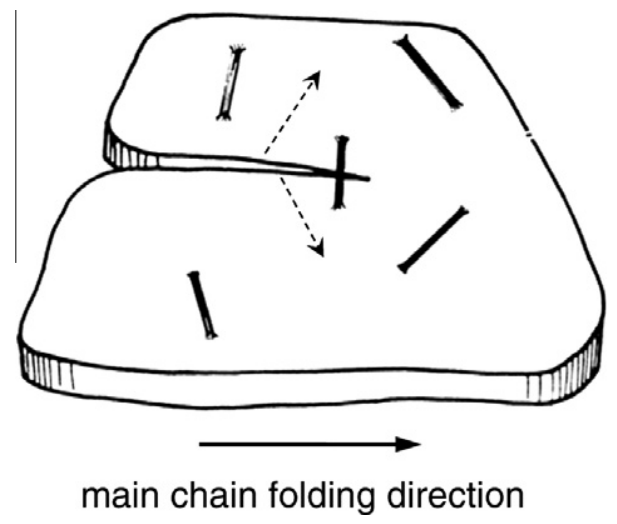

Fig. 7. Schematic bifurcation of a microcrack or cleavage propagating along a chain-folded plane in a crystal lamella (the bold bars stand for chain-folding topological defects; see text for details). consequently the smaller the microfibril diameter. However the sketch of Fig. 7 inspired from Tarin and Thomas [9] depicts how non-adjacent chain folds, that are not actual stress transmitters, can also play a role in the fragmentation of chain-folded lamellae. As a matter of fact, considering a microcrack or crystal cleavage propagating in a chain-folded plane, any non-adjacent chain fold such as the ones displayed in Fig. 7 generates a barrier effect that is likely to promote bifurcation. This kind of bifurcation will result in secondary microcracks leading to smaller crystal blocks, and thereby to slender microfibrils. The phenomenon of microcrack or cleavage bifurcation has been a matter of extensive experimental and theoretical studies on various kinds of materials such metal alloys [58,59], ceramics $[60]$ and polymers $[61,62]$ that support the present hypothesis.

One cannot discard the eventuality that an obstacle ahead of a propagating microcrack such as in Fig. 7 may generate a microcrack blunting effect. This would result in a mixture of microcracks and plastic shear within the crystal fragments that is consistent with Peterlin's and Takayanagi's models. This discussion is yet beyond the purpose of the present paper.

It is worth pointing out that if melting-recrystallization actually occurs during the course of the fibrillar transformation the bundles of molten chains or protofibrils resulting from the extraction of blocks from the crystalline lamellae should retain the width of the blocks. This is the way how the diameter of the final crystalline microfibril can keep the memory of the initial morphology in spite of the transitory melting step. In contrast, the long period of the recrystallized material should be mainly dependent on the actual temperature of the melt, which strongly depends on the intensity of the self-heating effect.

\section{Conclusion}

The fibrillar transformation in semi-crystalline polymers, far below the melting point, involves a destructionreconstruction of the semi-crystalline microstructure, analogous to actual strain-induced melting-recrystallization phenomenon, that obliterates most of the structural charac- 
teristics of the initial lamellar microstructure. The change of long period that only depends on the draw conditions is the most relevant hint of this metamorphosis.

In contrast, the present data give evidence that, through its role on the lamella fragmentation process, the interphase at the crystal-amorphous boundary has a direct incidence on the generation of the nascent microfibrils, more particularly on their diameter. This microfibril structural parameter proved thus to be more related to topological factors of the initial lamellar structure than to experimental conditions. The partly or thoroughly molten bundles of chains or protofibrils that are extracted from the crystalline lamellae and that subsequently recover a periodic semi-crystalline structure do retain the memory of some topological features of the lamellar microstructure through the mechanism of fragmentation. It is suggested that the chain topology that governs the distribution of the stress at a local scale on the crystalline lamella surface plays a major role in the propagation of microcracks from which are formed the crystal blocks. Not only the direct stress transmitters that carry the load between adjacent crystallites but also all topological defects gathered in the interphase during the morphogenesis of the lamellar microstructure contribute to the memory effect.

The fingerprint of the morphogenesis of the isotropic semi-crystalline material in the fibrillar transformation thus lies in the width of the microfibrils, that is reminiscent of the fragmentation process. This conclusion is consistent with the hypothesis from several authors that the fibrillation process is connected with the fragmentation of the mosaic block structure of the crystalline lamellae. One may reasonably believe that the misfit of the mosaic blocks is generated by the presence on the chain folding surface of topological defects that prevent the chain stems to settle into perfect crystallographic register. Hence, topological defects are directly connected with both the microcrack initiation and its bifurcation.

The obliteration of the initial long period necessarily means that strain-induced melting does occur upon tensile drawing. However, the incidence of the chain topology of the lamellar material on the microfibril width also means that the melting-recrystallization process occurs subsequently to the lamella fragmentation. This is the way the molten protofibrils may keep the memory effect or fingerprint of the morphogenesis of the isotropic solid.

Work is in progress for supporting the above conclusion via in situ SAXS experiments during drawing at various temperatures above RT. The significant reduction of cavitation with increasing draw temperature promotes the emergence of the meridian scattering and enables a thorough characterization of the fibrillar structure for the various materials of the present study in relation to thermal treatment.

\section{Acknowledgments}

The authors are indebted to Total-Petrochemicals (Belgium) for supplying the polymers and their molecular characteristics and to the European Synchrotron Radiation Facility (Grenoble, France) for time allocation on the D2AM beamline. Dr. C. Rochas is gratefully acknowledged for assistance in the SAXS experiments. The authors are also grateful to the French Ministry of Education and Scientific Research for the grant of a PhD fellowship to S. Humbert.

\section{References}

[1] Vincent PI. The necking and cold-drawing of rigid plastics. Polymer 1960;1:7-19.

[2] Peterlin A. Plastic deformation of polymers with fibrous structure. Colloid Polym Sci 1975;253:809-23.

[3] G'Sell C, Aly-Helal NA, Semiatin SL, Jonas JJ. Influence of deformation defects on the development of strain gradients during the tensile deformation of polyethylene. Polymer 1992;33:1244-54.

[4] Gaucher-Miri V, François P, Seguela R. On the mechanisms of initiation and propagation of plastic instability in polyethylene under tensile drawing. J Polym Sci, Polym Phys 1996;34:1113-25.

[5] Kobayashi K. As reported by Geil P H, Polymer Single Crystals. New York: John Wiley \& Sons Inc.; 1963.

[6] Ingram $P$, Kiho $H$, Peterlin A. The morphology of fibers from deformed polymer crystals. J Polym Sci, Polym Symp 1967;16:1857-68.

[7] Hosemann R, Loboda-Cackovic J, Cackovic H. Affine deformation of linear polyethylene during stretching and affine transformation to the original shape in the liquid state. J Mater Sci 1972;78:963-4.

[8] Schultz JM. Polymer Materials Science. Englewood Cliffs, NY: Prentice Hall Inc.; 1974.

[9] Tarin PM, Thomas EL. The role of inter- and intra-links in the transformation of folded chain lamellae into microfibrils. Polym Eng Sci 1979;19:1017-22.

[10] Reneker DH, Mazur J. Dispirations, disclinations, dislocations and chain twist in polyethylene crystals. Polymer 1983;24:1387-400.

[11] Lustiger A, Markham RL. Importance of tie molecules in preventing polyethylene fracture under long-term loading conditions. Polymer 1983;24:1647-54.

[12] Adams WW, Yang D, Thomas EL. Direct visualization of microstructural deformation processes in polyethylene. J Mater Sci 1986;21:2239-53.

[13] Kestenbach H-J, Petermann J. Plastic deformation of thin films of ultra-high-molecular-weight polyethylene. Polymer 1994;35:5217-24.

[14] Peterlin A. Folded chain model of highly drawn polyethylene. Polym Eng Sci 1969;9:172-81.

[15] Peterlin A. Drawing and extrusion of semi-crystalline polymers. Colloid Polym Sci 1987;265:357-82.

[16] Maher JW, Haward RN, Hay JN. Study of the thermal effects in the necking of polymers with the use of an infrared camera. J Polym Sci Polym Phys 1980;18:2169-79.

[17] Butler MF, Donald AM, Bras W, Mant GR, Derbyshire GE, Ryan AJ. A real-time simultaneous small- and wide-angle X-ray scattering study of in-situ deformation of isotropic polyethylene. Macromolecules 1995;28:6383-93.

[18] Jiang Z, Tang Y, Rieger J, Enderle H-F, Lilge D, Roth SV, et al. Two lamellar to fibrillar transitions in the tensile deformation of highdensity polyethylene. Macromolecules 2010;43:4727-32.

[19] Forgacs P, Sheromov MA, Tolochko BP, Mezentsev NA, Pindurin VF. The use of synchrotron radiation for study of structural changes in polymers during phase transition and deformation. J Polym Sci, Polym Phys 1980;18:2155-68.

[20] Yeh GS, Flook D, Asakawa T, Chen R, Jarvis P. Mechanism of necking as revealed by ultrasonic cavitation of polyethylene single crystals. J Macromol Sci, Phys 1972;6:635-54.

[21] Kajiyama T, Okada T, Takayanagi M. Role of mosaic block structure on the onset of deformation and fatigue of bulk crystallized PE. J Macromol Sci, Phys 1974;9:35-69.

[22] Suehiro K, Terashima T, Takayanagi M. Change of mosaic block size of bulk polyethylene in drawing processes. J Mater Sci 1974;9:1563-8.

[23] Hosemann R, Loboda-Cackovic J, Cackovic H. Plasto-elasticity of high polymers based on the analysis of polyethylene stretched till natural draw ratio. Colloid Polym Sci 1976;254:782-94.

[24] Schultz JM. Microstructural aspects of failure in semicrystalline polymers. Polym Eng Sci 1984;24:770-85.

[25] Hiss R, Hobeika S, Lynn C, Strobl G. Network stretching, slip processes and fragmentation of crystallites during uniaxial drawing of polyethylene and related copolymers. A comparative study. Macromolecules 1999;32:4390-403. 
[26] McCready MJ, Schultz JM, Lin JS, Hendricks RW. Effect of crystallization time on the properties of melt-crystallized linear polyethylene. J Polym Sci, Polym Phys 1979;17:725-40.

[27] Nitta K-H, Takayanagi M. Role of tie molecules in the yielding deformation of isotactic polypropylene. J Polym Sci, Polym Phys 1999;37:357-68.

[28] Nitta K-H, Takayanagi M. Tensile yield of isotactic polypropylene in terms of a lamellar-cluster model. J Polym Sci, Polym Phys 2000;38:1037-44.

[29] Nitta K-H, Takayanagi M. Novel proposal of lamellar clustering process for elucidation of the tensile yield behavior of linear polyethylenes. J Macromol Sci, Phys 2003;342:107-26.

[30] Humbert S, Lame O, Vigier G. Polyethylene yielding behaviour: what is behind the correlation between yield stress and crystallinity? Polymer 2009;50:3755-61.

[31] Humbert S, Lame O, Chenal JM, Rochas C, Vigier G. New insight on initiation of cavitation in semicrystalline polymers: in situ SAXS measurements. Macromolecules 2010;43:7212-21.

[32] Bayer RK. Structure transfer from a polymeric melt to the solid-state. 1. The influence of chain entanglements in linear polyethylene. Colloid Polym Sci 1991;269:421-32.

[33] Haward RN. Strain hardening of thermoplastics. Macromolecules 1993;26:5860-9.

[34] Hubert L, David L, Seguela R, Vigier G, Corfias-Zuccalli C, Germain Y Physical and mechanical properties of polyethylene for pipes in relation to molecular architecture. II. Short-term creep of isotropic and drawn materials. J Appl Polym Sci 2002;84:2308-17.

[35] Kurelec L, Teeuwen M, Schoffeleers H, Deblieck R. Strain hardening modulus as a measure of environmental stress crack resistance of high density polyethylene. Polymer 2005;46:6369-79.

[36] Bartczak Z. Effect of chain entanglements on plastic deformation behavior of linear polyethylene. Macromolecules 2005;38:7702-13.

[37] Cazenave J, Seguela R, Sixou B. Short-term mechanical and structural approaches for the evaluation of polyethylene stress crack resistance. Polymer 2006;47:3904-14.

[38] Seguela R. On the natural draw ratio of semi-crystalline polymers: review of the mechanical, physical and molecular aspects. Macromol Mater Eng 2007;292:235-44.

[39] Maxwell AS, Pilkington G. Prediction of environmental stress cracking resistance in linear low density polyethylenes. Polym Eng Sci 2008;48:360-4.

[40] Cheng JJ, Polak MA, Penlidis A. A tensile strain hardening test indicator of environmental stress cracking resistance. J Macromol Sci, Pure Appl Chem 2008;45:599-611.

[41] Humbert S, Lame O, Chenal JM, Rochas C, Vigier G. Small strain behavior of polyethylene: in situ SAXS measurements. J Polym Sci, Polym Phys 2010;48:1535-42.

[42] Humbert S, Lame O, Séguéla R, Vigier G. A re-examination of the elastic modulus dependence on crystallinity in semi-crystalline polymers. Polymer 2011;52:4899-909.
[43] Wunderlich B. Macromolecular Physics, Vol.1. Crystal structure, Morphology Defects, New York: Academic Press; 1973.

[44] Strobl GR, Hagedorn W. Raman spectroscopic method for determining the crystallinity of polyethylene. J Polym Sci, Polym Phys 1978; $16: 1181-93$.

[45] Stribeck N. Analysis of SAXS fiber patterns by means of projections. ACS Symp Ser 2000;739:41-56.

[46] Bear RS, Bolduan OEA. Diffraction by cylindrical bodies with periodic axial structure. Acta Crystallogr 1950;3:236-41.

[47] Bolduan OEA, Bear RS. General nature of the extension of structure transverse to collagen fibril axes. J Polym Sci 1951;6:271-84.

[48] Statton WO. Polymer texture: arrangement of crystallites. J Polym Sci 1959;41:143-55.

[49] Hosemann R. Crystallinity in high polymers, especially fibers. Polymer 1962;3:349-92.

[50] Alexander L. X-Ray Diffraction Methods in Polymer Science. New York: Wiley; 1969.

[51] Guinier A, Fournet G. Small-Angle Scattering of X-Rays. New York: Wiley; 1955

[52] Kitamaru R, Horii F. NMR approach to the phase structure of linear polyethylene. Adv Polym Sci 1978;26:137-78.

[53] Mandelkern L, Alamo RG, Kennedy MA. The interphase thickness of linear polyethylene. Macromolecules 1990;23:4721-3.

[54] Alamo RG, Viers BD, Mandelkern L. Phase structure of random ethylene copolymers. A study of co-unit content and molecular weight as independent variables. Macromolecules 1993;26: 5740-7.

[55] Singhal A, Fina LJ. Dynamic two-dimensional infra-red spectroscopy of the crystal-amorphous interphase region in low-density polyethylene. Polymer 1996;37:2335-43.

[56] Balijepalli S, Rutledge GC. Molecular simulation of the intercrystalline phase of chain molecules. J Chem Phys 1998;109:6523-6.

[57] Rastogi S, Terry AE. Morphological implications of the interphase bridging crystalline and amorphous regions in semi-crystalline polymers. Adv Polym Sci 2005;180:161-94.

[58] Chen J, Qiao Y. Bifurcation and deviation of cleavage paths at through-thickness grain boundaries. Metallurg Mater Trans A. Phys Metallurg Mater Sci; 39: 2040-2044.

[59] Birosca S, Buffiere JY, Karadge M, Preuss M. 3-D observations of short fatigue crack interaction with lamellar and duplex microstructures in a two-phase titanium alloy. Acta Mater 2011;59:1510-22.

[60] Bermejo R, Danzer R. High failure resistance layered ceramics using crack bifurcation and interface delamination as reinforcement mechanisms. Eng Fracture Mechanics 2010;77:2126-35.

[61] Murphy N, Ali M, Ivankovic A. Dynamic crack bifurcation in PMMA. Eng Fracture Mechanics 2006;73:2569-87.

[62] Le Cam J-B, Toussaint E. The mechanism of fatigue crack growth in rubbers under severe loading: the effect of stress-induced crystallization. Macromolecules 2010;43:4708-14. 